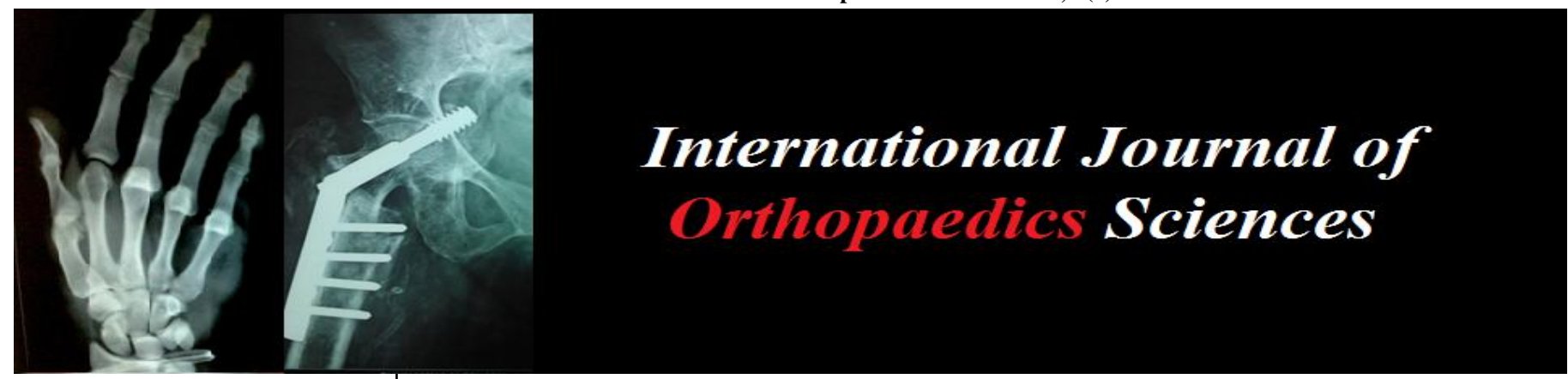

E-ISSN: 2395-1958

P-ISSN: 2706-6630

IJOS 2020; 6(4): 212-216

(C) $2020 \mathrm{IJOS}$

www.orthopaper.com

Received: 07-08-2020

Accepted: 11-09-2020

Vijay Baba N

Associate Professor, Department

of Orthopaedics, ACS Medical

College and Hospital,

Velappanchavadi, Chennai,

Tamil Nadu, India

Prasanna C

Associate Professor, Department of Orthopaedics, PSG Hospitals, PSGIMSR, Peelamedu,

Coimbatore, Tamil Nadu, India

Corresponding Author:

Prasanna C

Associate Professor, Department of Orthopaedics, PSG Hospitals, PSGIMSR, Peelamedu,

Coimbatore, Tamil Nadu, India
Original Article

\section{Analysis of surgical management of proximal humeral fractures}

\author{
Vijay Baba $\mathbf{N}$ and Prasanna $\mathrm{C}$ \\ DOI: https://doi.org/10.22271/ortho.2020.v6.i4d.2341
}

Abstract

Aim: To assess the outcome of fractures of proximal humerus managed surgically.

Materials and Methods: This prospective clinical study is an analysis of 22 cases of surgically managed proximal humeral fractures, undertaken at the Department of Orthopaedics \& Traumatology, Govt. General Hospital, Chennai. Standard anteroposterior radiographs of the affected shoulder were taken in all patients and most of them were further evaluated with Neer's three view trauma series. CT scan was done in patients with complex fracture dislocations, to delineate the fracture pattern and the direction of dislocation. The indications for surgery were displacement more than $1 \mathrm{~cm}$ and angulation $>45^{\circ}$. Patients not satisfying these criteria were treated conservatively and not included in this study. All the patients were operated by the standard anterior deltopectoral approach. All the patients were followed up monthly for the first 3 months and later every 3 months. During follow-up patients were clinically evaluated for pain, function and rotation. Radiological evidence of fracture union was observed by serial $\mathrm{x}$-rays.

Result: Majority of the injured patients were males (72\%). Mean age of the study population was 36.75 years. RTA was the most common mode of injury (36.3\%). There were no bilateral fractures; all were right handed persons and the dominant arm was involved in $16(72.7 \%)$ patients. Early complications were encountered in $6(25 \%)$ patients and late complications were encountered in $8(30 \%)$ patients Conclusion: This study concluded that functional outcome of two part fractures is better than three part and four part fractures and the results are better with fractures than with fracture dislocations.

Keywords: proximal humerus, fracture, management, surgery

\section{Introduction}

Fractures of the proximal humerus are challenging to diagnose and treat. They are not uncommon, accounting for $4 \%$ to $5 \%$ of all fractures ${ }^{[1,2]}$. Emphasis is placed on complete and accurate diagnosis and formulation of safe and simple techniques for restoration of stability, fracture healing, cuff integrity, motion and function.

Diagnosis has been facilitated with adoption of three-right angled trauma series [3-5] supplemented with CT or MRI. With more standard use of four-segment classification system for fracture and fracture dislocation ${ }^{[6-8]}$ a protocol for management and comparison of long term outcome of similar injuries had been made possible.

There have been improvements in fixation techniques during open reduction and in the understanding of the role of prosthetic replacement ${ }^{[9-12]}$ to maximise anatomic restoration while minimising immobilisation time during which stiffness develops.

With the advent of improved fixation techniques the elderly no longer need be denied effective surgical treatment, especially at a time in life, when the shoulders are often needed for ambulation with canes and crutches. Maintenance of good shoulder function may make a good difference for their independent life style. Hence the present prospective clinical study was conducted to assess the outcome of fractures of proximal humerus managed surgically.

\section{Materials and Methods}

This prospective clinical study is an analysis of 22 cases of surgically managed proximal humeral fractures, undertaken at the Department of Orthopaedics \& Traumatology, Govt. General Hospital, Chennai. 


\section{Methodology}

Standard anteroposterior radiographs of the affected shoulder were taken in all patients and most of them were further evaluated with Neer's three view trauma series which involves the AP view in the plane of scapula, lateral view in the plane of scapula and axillary lateral view. CT scan was done in patients with complex fracture dislocations, to delineate the fracture pattern and the direction of dislocation. The indications for surgery were displacement more than $1 \mathrm{~cm}$ and angulation $>45^{\circ}$. Patients not satisfying these criteria were treated conservatively and not included in this study. All the patients were operated by the standard anterior deltopectoral approach.

\section{Surgical procedure (Figure 1.1)}

Under general anaesthesia, patients were positioned supine on the operating table. A sand bag was wedged under the medial border of scapula to push the affected shoulder forward while allowing the arm to fall backward, thus opening up the front of the joint. Elevation of the head end of the table considerably reduced the bleeding. An incision was made from the coracoid and carried distally in the line of deltopectoral groove to the deltoid insertion. The internervous plane was dissected between deltoid, which is supplied by axillary nerve and pectoralis major which is supplied by pectoral nerves. In most cases, cephalic vein was preserved with either the deltoid or pectoralis major. In some it was ligated. The deltoid was partially erased from the clavicle for better exposure and retracted laterally and superiorly. The long head of biceps found under the insertion of pectoralis major was used as a guide to the interval between greater and lesser tuberosities. It also helped expose the rotator interval between the anterior part of supraspinatus and superior edge of subscapsularis. With the arm abducted 70-90 degrees the tuberosities, humeral head were exposed. Fracture fragments were reduced with bone holding forceps and reduction confirmed with image intensifier. Implants were selected according to the geometry of the fracture.

\section{Cancellous screw fixation}

For cancellous screw fixation the displaced greater tuberosity fragment was reduced with bone holding forceps and drill holes made with $3.2 \mathrm{~mm}$ dill bit and $6.5 \mathrm{~mm}$ cancellous screws inserted after tapping the near cortex.

\section{Buttress plating}

For AO " $\mathrm{T}$ " buttress plating, the fracture fragments were reduced. ' $\mathrm{T}$ ' plate was placed on the lateral aspect and stabilised with cancellous screws for the tuberosity fragments and cortical screws for the shaft.

\section{Tension band wiring}

For Tension band wiring, ' $k$ ' wires were passed from the greater tuberosity into the shaft. The ' $k$ ' wires were cut close to the tuberosity and bent. Drill-hole was made in the shaft and a $18 \mathrm{G} \mathrm{SS}$ wire passed in the form of 'figure of 8' from the ' $k$ ' wires to the drill hole, stabilising the fracture fragments.

\section{Minimal Fixation with ' $k$ ' wire}

For minimal fixation with 'k' wires, the 'k' wires were passed from the shaft to the head of humerus and another ' $k$ ' wire from the greater tuberosity to the medial cortex of humeral shaft. incision was extended down to expose the shaft. Subscapsularis was retracted medially with lesser tuberosity to expose the interior of joint. The articular head fragment was removed and the joint cleared of blood clots and bone debris. The intra articular portion of biceps was identified as it attaches to the supraglenoid tubercle of scapula. If it were not injured, it was preserved by retracting it laterally. The stem diameter and length required in the proximal 12 to $15 \mathrm{~cm}$ of the medullary canal were estimated. Once the stem size and neck length were determined the prosthesis was inserted by hand in 35-40 degrees of retroversion. The amount of retroversion was determined by flexing the elbow to 90 degrees and palpating the epicondyles. Suture passed through tuberosities or tendon bone junction was passed through holes in the neck of prosthesis. Anatomic reduction of tuberosities was done beneath the collar or head of prosthesis and sutures tightened.

Polymethyl methacrylate cement was used to secure the prosthesis in bone, if fixation was not adequately stable.

\section{Fracture dislocation}

In irreducible fracture dislocations and head splitting fractures the coracoid was predrilled and osteotomised and retracted with the tendon. Arm was externally rotated and blunt instrument passed between subscapsularis and capsule and stay sutures applied. It was divided one inch from its insertion and retracted. Capsule was incised longitudinally to open the joint and reduce the articular fragment.

In all patients, the rotator interval between anterior edge of supraspinatus and superior edge of subscapsularis was closed with multiple interrupted sutures. The deltoid was reattached to the clavicle and wound irrigated and closed over suction drain.

\section{Post-Op Care and Rehabilitation}

Prophylactic antibiotics which were started before surgery were continued for 48 and 72 hours postoperatively.

In a few ice packs were used to decrease the swelling. Passive elbow flexion and extension were started by 24 to 48 hours.

Sutures were removed by 10th postoperative day.

Phase I: Exercises consisting of pendulum exercises were encouraged from the first week. Gentle passive forward flexion and internal and external rotation were started by third or fourth week.

Phase II: Exercises consisting of active range of motion exercises and resistive exercises were started by 4 to 6 weeks. Phase III: Exercises consisting of advanced stretching and strengthening exercises were started by 3 months. Light weight lifting was started after 3 months.

\section{Follow-up}

All the patients were followed up monthly for the first 3 months and later every 3 months. During follow-up patients were clinically evaluated for pain, function and rotation. Radiological evidence of fracture union was observed by serial x-rays. (Figure 1.2)

\section{Statistical Analysis}

The recorded data was compiled and entered in a spreadsheet computer program (Microsoft Excel 2010) and then exported to data editor page of SPSS version 19 (SPSS Inc., Chicago, Illinois, USA). Descriptive statistics included computation of percentages.

\section{Hemiarthroplasty}

For hemiarthroplasty the standard anterior deltopectoral 
Table 1: age and gender wise distribution of study subjects

\begin{tabular}{|c|c|c|c|c|}
\hline Age group & No. of patients & Percentage & Males & Females \\
\hline $0-10$ & 0 & 0 & 0 & 0 \\
\hline $11-20$ & 4 & 18 & 3 & 1 \\
\hline $21-30$ & 4 & 18 & 4 & 0 \\
\hline $31-40$ & 6 & 27 & 4 & 2 \\
\hline $41-50$ & 3 & 13 & 3 & 0 \\
\hline $51-60$ & 4 & 18 & 2 & 2 \\
\hline $61-70$ & 1 & 6 & 0 & 1 \\
\hline Total & 22 & 100.0 & 16 & 6 \\
\hline
\end{tabular}

Table 2: distribution of study subjects according to mode of injury

\begin{tabular}{|c|c|c|}
\hline variables & No. of patients & Percentage \\
\hline \multicolumn{3}{|l|}{ Mode of injury } \\
\hline RTA & 8 & 36.3 \\
\hline FFH & 4 & 18.18 \\
\hline Epilepsy & 2 & 9.09 \\
\hline Fall at ground level & 6 & 27.27 \\
\hline Electrocution & 2 & 9.09 \\
\hline \multicolumn{3}{|l|}{ Side Involved } \\
\hline Dominant (right) & 16 & 72.7 \\
\hline Non dominant (left) & 6 & 27.3 \\
\hline
\end{tabular}

Table 3: distribution of study subjects according to type of fracture and dislocation type

\begin{tabular}{|c|c|}
\hline Variables & No. of patients \\
\hline Fracture type & 21 \\
\hline Closed Fracture & 1 \\
\hline Open Fracture & 11 \\
\hline Neer's Type & 8 \\
\hline 2 part & 3 \\
\hline 3 part & \\
\hline 4 part & 12 \\
\hline Dislocation & 10 \\
\hline No dislocation & 3 \\
\hline Dislocation & 4 \\
\hline 2 Part & 3 \\
\hline 3 Part & \\
\hline 4 Part & \\
\hline &
\end{tabular}

Table 4: distribution of study subjects according to type of Implant placed

\begin{tabular}{|c|c|c|c|c|}
\hline Implants & No. of patients & 2 part & 3 part & 4 part \\
\hline T Buttress plate & 7 & 3 & 3 & 1 \\
\hline TBW & 3 & 0 & 3 & 0 \\
\hline K wire & 7 & 4 & 2 & 1 \\
\hline Hemiarthroplasty & 1 & 0 & 0 & 1 \\
\hline Cancellous Screws & 4 & 4 & 0 & 0 \\
\hline
\end{tabular}

Table 5: distribution of early and late complications

\begin{tabular}{|c|c|}
\hline Complications & No. of patients \\
\hline Early & 2 \\
\hline Skin necrosis & 1 \\
\hline Wound gaping & 2 \\
\hline Axillary nerve damage & 1 \\
\hline Deltoid atony & \\
\hline Late & 0 \\
\hline Non union & 2 \\
\hline Mal union & 3 \\
\hline Joint Stiffness & 1 \\
\hline Heterotopic ossification & 1 \\
\hline Instability & 1 \\
\hline Infection &
\end{tabular}

\section{Discussion}

In this study, we have analyzed 22 cases of surgically managed proximal humeral fractures in our hospital. There was male preponderance in our study $16(72 \%)$ which was the same as the study by Flatow et al. ${ }^{[13]}$ In a study conducted by Hawkins et al. ${ }^{[14]}$ involving 15 patients of proximal humeral fracture, there was female preponderance. This is thought to be a result of advanced osteoporosis.

In our study the average age of the patients was 36.75 years which was much lower than reports by Hawkins et al. ${ }^{[14]}$ and Flatow et al. ${ }^{[13]}$ and Cornell et al. ${ }^{[15]}$

RTA was the most common mode of injury in our study, probably because majority of the patients were in the younger age group (average 36.75). In a study by Flatow et al. ${ }^{[13]}$ fall on the arm was the predominant mode of injury probably reflecting the increase in average age of the patients (53 mean) in their study.

In our study, unusual mode of injury like seizures was present in two patients and electrocution in two patients. There was a predominance of two part fracture in our study $(50 \%)$ of which greater tuberosity fractures were the most common. Associated dislocations were present in $45 \%$ of the patients. With reduction of glenohumeral dislocation if tuberosity fragment remained displaced $>1 \mathrm{~cm}$ or angulated $>45$ degrees, ORIF was done. Repair in such patients restored the dynamic stability by reattachment of the muscles of the rotator cuff. Flatow et al. ${ }^{[13]}$ in a series of 12 patients reported $50 \%$ excellent results and $50 \%$ good results in patients treated by ORIF for two part greater tuberosity fracture.

Closed treatment of three part fracture is associated with moderate pain, poor motion and disability. ORIF was associated with good to excellent results in more than $80 \%$ of patients in a report by Hawkins et al. ${ }^{[14]}$ and recommend operative treatment for healthy active individuals who have a three part fracture of the proximal humerus. Cornell et al. ${ }^{[15]}$ reported good results in 10 of 13 patients treated with screwtension band technique for 3 part fracture. Prosthetic replacement for 3 part fracture has been used by several authors but we have not done prosthetic replacement for three part fracture in our study.

In the treatment of four part fracture and fracture dislocations, less than $10 \%$ good or excellent results are obtained with either closed or open reduction or internal fixation. Isolated reports of revascularisation of humeral head following open reduction and internal fixation indicate satisfactory healing. Neer and Rockwood have reported nearly $90 \%$ excellent results with an improved technique utilizing long deltopectoral approach and better rehabilitation. ${ }^{[16]}$ This has become the preferred technique of most surgeons and we have also used the same technique. From the data presented in this study, we have demonstrated that majority of the patients had no pain or only mild pain $(80 \%)$ which is comparable to the study conducted by Hawkins et al.15 and Flatow et al. ${ }^{[13]}$

The average active elevation in our study in two part fractures was 149 degrees and average external rotation was 62.5 degrees which are comparable to the study by Flatow et al. ${ }^{[13]}$ in a study of 12 patients of two part fractures treated surgically.

The average elevation in our study with three part fracture was 112.85 degrees and external rotation was 45 degrees which are also comparable to the study by Hawkins et al. ${ }^{[14]}$ of 15 cases of 3 part proximal humerus fractures treated surgically.

We also have seen few complications in our study. Malunion of greater tuberosity fragment in a patient with 3 part fracture treated with buttress plating resulted in restriction of abduction and impingement. Another patient had malunion of 
surgical neck, but had excellent functional result reflecting the fact that radiological outcome may not imply functional outcome.

Heterotopic ossification occurred in one patient with 2 part fracture dislocation, probably because the patient had received native treatment in the form of many attempted reductions and massage. Several authors have reported an incidence of upto $10 \%$ of heterotopic ossification in proximal humeral fractures. There were no non-unions or radiographic evidence of avascular necrosis or deep infection in our study.

Finally a prolonged, closely monitored and well defined program of rehabilitation was necessary to obtain the best functional results. We have followed the three phase rehabilitation protocol of Hughes and Neer ${ }^{[17]}$ in all our patients and this has provided good results. For some patients this had taken as long as a year to achieve nearly full range of motion and function.

\section{Conclusion}

The present study concluded that: functional outcome of two part fractures is better than three part and four part fractures; the results are better with fractures than with fracture dislocations; in severely comminuted fractures, where anatomy cannot be restored without extensive soft tissue dissection, fixation with ' $\mathrm{k}$ ' wires and screws gave better functional results and results are best when operative method results in stable fixation that allows early passive mobilization.

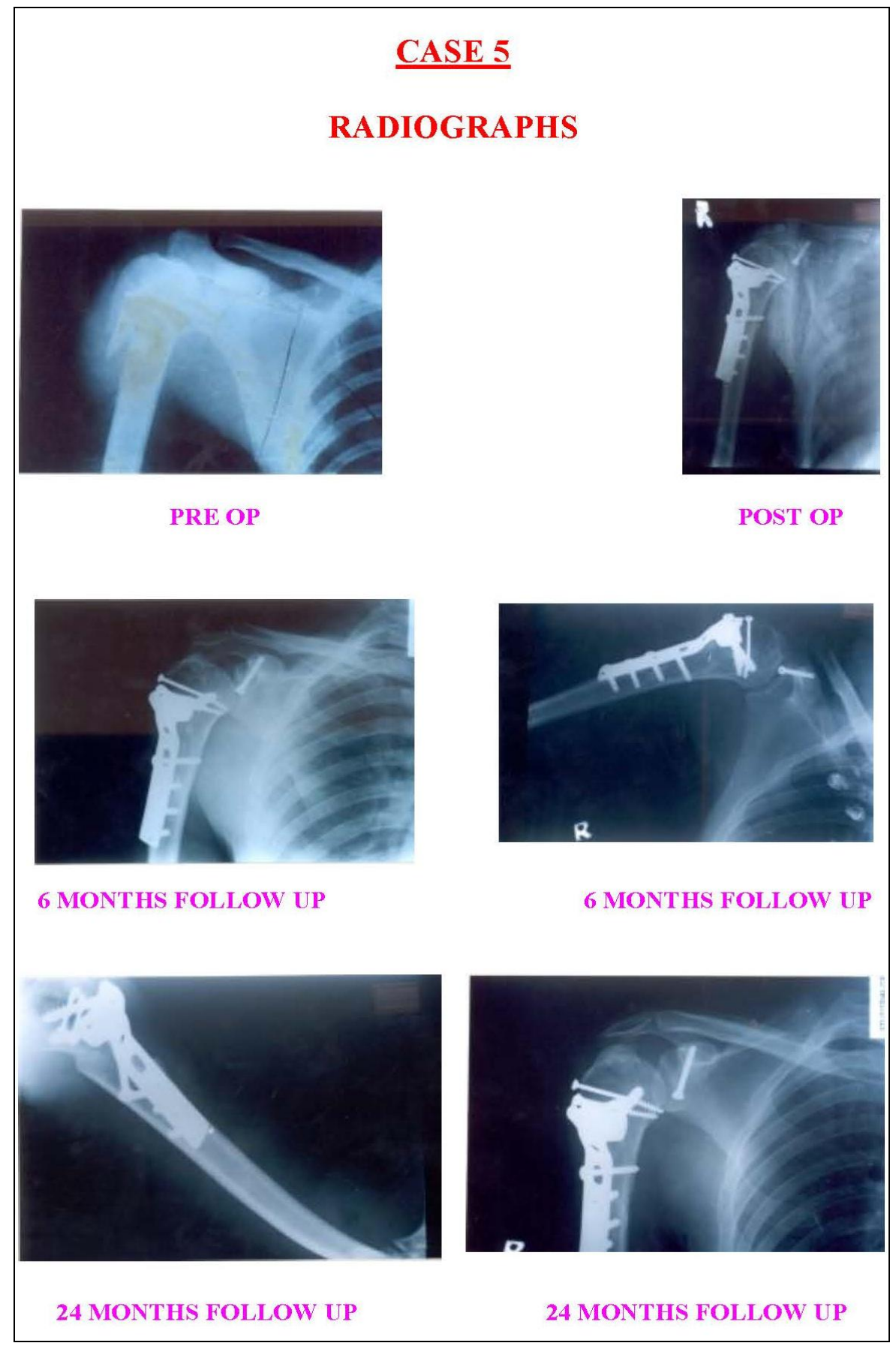

Fig 1. Radiographs

\section{References}

1. Tom R. Norris, Fractures and fracture dislocations of the glenohumeral complex, J.B. Lippin-Cott Company,
Philadelphia, 1993;29:405-421.

2. Tom R Norris, Skeletal trauma. Fracture of the proximal humerus and dislocations of the shoulder. $1^{\text {st }}$ Edition. 
2(39):1201-1279.

3. Post M. Fractures of the upper humerus. Orthop Clin North Am. 1980;11(2):239-52

4. Hawkins RJ, Angelo RL. Selecting treatment, avoiding pitfalls; displaced proximal humeral fracture. Management of shoulder problems, Orthop Clin North Am 1987;18(3):421-31.

5. Robert $\mathbf{J}$ Neviaser. Radiologic assessment of the shoulder, plain \& arthrographic. Orthopaedic Clinics of North America 1987;18(3):343-462.

6. Bernstein J, Adler LM, Blank JE, Dalsey RM, Williams GR, Iannotti JP. Evaluation of the Neer system of classification of proximal humeral fractures with computerized tomographic scans and plain radiographs. J Bone Joint Surg Am. 1996;78(9):1371-5.

7. Sidor ML, Zuckerman JD, Lyon T, Koval K, Cuomo F, Schoenberg N. The Neer classification system for proximal humeral fractures. An assessment of interobserver reliability and intraobserver reproducibility. J Bone Joint Surg Am. 1993;75(12):1745-50.

8. Daughtery TS, Linda Jones KL. Campbell's operative Orthopaedics, $9^{\text {th }}$ Edition, 3, 2286-96.

9. Iannotti JP, Williams GR. Total shoulder arthroplasty. Factors influencing prosthetic design. Orthop Clin North Am. 1998;29(3):377-91.

10. Post M. Constrained Arthroplasty of the Shoulder. Orthop Clin North Am 1987;18(3):455-62.

11. Hattrup SJ. Indications, technique and results of shoulder arthroplasty. Orthop Clin North Am. 1998;29(3):445-66.

12. Brown TD, Bigliani LU. Complications with humeral head replacement. Orthop Clin North Am. 2000;31(1):77-90.

13. Flatow EL, Cuomo F, Maday MG, Miller SR, McIlveen SJ, Bigliani LU. Open reduction and internal fixation of two-part displaced fractures of the greater tuberosity of the proximal part of the humerus. J Bone Joint Surg Am. 1991;73(8):1213-8.

14. Hawkins RJ, Bell RH, Gurr K. The three-part fracture of the proximal part of the humerus. Operative treatment. J Bone Joint Surg Am. 1986;68(9):1410-4.

15. Cornell CN, Levine D, Pagnani MJ, Internal fixation of proximal humerus fracture using the screw-tension band technique. J Ortho trauma 1994;8(1):23-7.

16. Neer CS, Rockwood CA. Fractures and dislocation of the shoulder, in fractures (Eds. CA Rockwood and DP Green). JB Lippincott, Philadelphia, 1984, 675- 707.

17. Hughes M, Neer CS. 2nd. Glenohumeral joint replacement and postoperative rehabilitation. Phys Ther. 1975;55(8):850-8. 